\title{
EARLY CHILDHOOD CARIES IN MULTILINGUAL COMMUNITY
}

\author{
Ivan Tušek', Bernadette O'Rourke ${ }^{2}$, Charles Lekić3 ${ }^{3}$ Jasmina Tušek ${ }^{4}$, Branislav Tušek ${ }^{5}$ \\ ${ }^{1}$ Department of Paediatric and Preventive Dentistry, Faculty of Medicine, University of Novi Sad and Dental Clinic of Vojvodina, Novi Sad, Serbia \\ ${ }^{2}$ Intercultural Research Centre, School of Management and Languages, Heriot-Watt University, Edinburgh, United Kingdom \\ ${ }^{3}$ Department of Preventive Dental and Paediatric Dentistry, Faculty of Dentistry, University of Manitoba, Winnipeg, Manitoba, Canada \\ ${ }^{4}$ Private Dental Practice Palmadent, Novi Sad, Serbia \\ ${ }^{5} \mathrm{Clinic}$ for Obstructive Pulmonary Diseases and Acute Pneumopathies, Institute for Pulmonary Diseases of Vojvodina, Sremska Kamenica, \\ Serbia
}

\section{SUMMARY}

Objective: The aim of the study was to determine the prevalence and severity of early childhood caries (ECC) among different social groups of preschool children in ethnic and multilingual diverse community such as South Backa District (SBD), Republic of Serbia.

Methods: This survey was a cross-sectional analytical study and sample type has been projected by simple random choice of 13-71 months old children together with their parents of varied socioeconomic status (SES) and nationality in SBD. Preschool children were randomly selected through a two-stage cluster sampling procedure and parents were invited to answer the questionnaire regarding SES, native language, education, and income issues. The WHO caries diagnostic criterion was used and the severity of ECC was defined by Wine's modified criteria. The data was further analyzed using the SPSS for Windows Microsoft Excel, version 21. The percentage of caries-free children was compared using the $x^{2}$ test, and one-way ANOVA was used to compare the mean disease indices at the $5 \%$ significance.

Results: A total of 341 children were examined and the prevalence of ECC was 30.5\%. "White spot" initial caries lesions were the most prevalent form and the highest disease frequency was found in male children $(p=0.038)$, who did not speak official Serbian language $(p=0.009)$, in children of the part-time employed parents $(p<0.001)$, with elementary education $(p=0.001)$, in low monthly income families $(p=0.023)$, and Roma ethnic group.

Conclusions: The complex interaction of risk factors like social environment along with ethnicity and Serbian language ignorance had a significant influence on the prevalence and severity of ECC in preschool children of this multi-ethnic region.

Key words: ECC, multilingualism, social class, ethnicity

Address for correspondence: I. Tušek, University of Novi Sad, Faculty of Medicine, Dental Clinic of Vojvodina, Department of Paediatric and Preventive Dentistry, Hajduk Veljkova 12, 21000 Novi Sad, Serbia. E-mail: ivan.tusek@mf.uns.ac.rs

https://doi.org/10.21101/cejph.a6345

\section{INTRODUCTION}

Early childhood caries (ECC) is a serious public health problem both in developed and undeveloped countries. This chronic infectious disease is particularly present in socially disadvantaged children and it has been described as a public, social, political, behavioural, medical, psychosocial, economic, and dental problem (1). Therefore, many researchers have attempted to expand basic microbiological models for ECC development, and to include various social, demographic and behavioural factors such as ethnicity, family income, maternal education level, family status, and parental knowledge (2). Children from the minority ethnic groups or immigrant children (3) have been found to be at higher risk of caries, too. Numerous studies suggested that ECC was more commonly found in children who lived in poverty (4), who were of ethnic and racial minorities (3), from single parent family (5), with parents of low educational level, especially those of illiterate mothers (6). The possible influence of socioeconomic status (SES) on the dental health may also be a consequence of difference in dietary habits and the role of sugar in the diet (7). The
American Academy of Pediatric Dentistry (AAPD) defined ECC as: "the presence of one or more decayed, missing or filled tooth surfaces in any primary tooth in children 71 months of age and younger" (8). A comprehensive review of the ECC occurrence, including numerous studies from Europe, Africa, Asia, the Middle East, and North America, found the highest prevalence in Africa and South-East Asia (9). Published studies showed higher ECC prevalence figures for 3-year-olds that ranged from 36 to $85 \%$ in Far East Asia region (10), whereas the figure reported in East Indian studies was $45.33 \%$ (11). Studies conducted in the Middle East (12) showed that the ECC prevalence in children 2-6 years of age was $50.1 \%$. In England, the USA and Canada's North, the prevalence of ECC varied between $7.0 \%, 12.0 \%$ and from $28 \%$ to $98.9 \%$, respectively (13). In some countries of South Eastern Europe the prevalence was reported to be $30 \%$ in Croatia (14), $64.65 \%$ in Bosnia (15), and $38.19 \%$ to $40.29 \%$ in Romania (16). In the South Backa District (SBD), as part of the Republic of Serbia, there seems to be an increased trend of ECC, and it can be linked with a rapid decrease of living standard, therapeutic approach to ECC treatment as well as with specific demographic, 
psychosocial and behavioural characteristics of this environment. Diverse ethnicities, languages, cultures, and social structures may be ECC risk factors that are unique to the young population of SBD. So, the aim of this study was to determine the prevalence of ECC and the degree of severity (type 1-5) among different social and ethnic groups of preschool children in this specific multilingual diverse community.

\section{MATERIALS AND METHODS}

This study was approved by the Committee of Human Research of the Medical Faculty of Novi Sad, process number: 1206/18. Children were examined only when they had a written consent form signed by their parents. The survey was cross-sectional analytical study of preschool children in the SBD. Sample type has been projected by simple random choice and contains both parents and their children from 13 to 71 months old, of different gender, SES and nationality. Dental survey comprised, and recorded within the case file, 341 children and the questionnaire comprised 682 of their parents. The multi-grade type sample has been elected in survey unit definition, which comprised $10 \%$ of children of the aimed population, and as a step of choice the following formula: $\mathrm{k}=\mathrm{N} / \mathrm{n}$ ( $\mathrm{k}$ - step of choice, $\mathrm{n}$ - number of units within sample, $\mathrm{N}$ - number of units in the basic set). Number of units in basic set $(\mathrm{N})$ has been determined by records of preschool institutions within certain municipalities of the SBD on the number of enrolled preschool children during 2018/19 year; share of $10 \%$ of preschool children has been established since it reflects the number of units within the sample (n). By implementing the step of choice $(\mathrm{k})$, based upon the records of the preschool institutions, units for the sample have been defined.

\section{Study Location}

The South Backa District is situated in the northern part of Serbia, it covers $4,016 \mathrm{~km}^{2}$ with 593,666 inhabitants. The fluoride concentration in drinking water is generally low $(<0.3 \mathrm{ppm} F)$. In addition to the multi-ethnic and multicultural characteristics of this region there are also differences in education, personal income and unemployment rates in this population. Assessing the presence of these variables is important in determining the correlation between the outlined demographic, multilingual, educational, and socioeconomic factors, and the prevalence of ECC. In the first stage, the parents were given specially designed questionnaire written in official (Serbian) and minority languages, with the personal data of parents and each child separately. The questionnaire was made up of 64 closed questions focusing on ethnicity, language disparity, demographic features, SES of the family, knowledge, attitudes and specific habits of minority groups of parents concerning diet, oral hygiene, fluoride prophylaxis, behaviour towards the oral as well as general health, the health information level of parents, etc. The dental examinations were conducted by a single well trained and calibrated dentist. The youngest group of children 13-24 months old were examined by a visual method, referred to as a "lift the lip" technique. Other children were examined with plane dental mirror and probe, using natural light, without previous brushing and drying teeth. Exams were performed in the kindergarten nursing room, except for children that lived in disadvantaged settlements, and who were examined "in the open air". All primary teeth were examined and early childhood caries (Fig. 1) were recorded using the WHO recognized indices of decayed, missing and filled teeth and surfaces $-\mathrm{dmft}$, dmfs, respectively. The authors decided to use Wine's classification, which included: labial-lingual caries lesions on the maxillary incisors and canines.

\section{Classification of ECC}

- The initial form (type 1) shows carious lesions in the form of white spots but without a breakdown of the enamel surface;

- The moderate form (type 2) shows carious lesions with a breakdown of the enamel surface and affecting one or two teeth or their surfaces;

- The middle form (type 3) shows carious lesions with a breakdown of the enamel surface and affecting more than two teeth or their surfaces;

- The severe form (type 4) shows the presence of two and more necrotic roots in the maxillary inter-canine section (MIS);

- The severe form with complications (type 5) shows the presence of two and more necrotic roots in the MIS with the presence of fistula and/or abscessed teeth.

The obtained clinical and questionnaire data were further analysed using the IBM SPSS Statistics for Windows, version 21. Descriptive statistics were calculated to determine the percentage of caries-free children, mean caries disease severity indices ( $\mathrm{dmft}$, $\mathrm{dmfs}$ ), and standard deviations of the mean for each variable investigated. The percentage of caries-free children were compared using $\chi^{2}$ test, and one-way ANOVA was used to compare the mean disease indices at $5 \%$ level of significance. P-values less than or equal to 0.05 were considered statistically significant.

\section{RESULTS}

A total of 341 children were examined, 191 (56.01\%) boys and $150(43.98 \%)$ girls. The prevalence of ECC in children 13-71 months old was $30.50 \%$. Out of those examined 237 (69.50\%) were caries free. In maxillary inter-canine section 1,751 deciduous teeth were healthy, 290 were decayed and 5 were filled. Every child had on average 0.87 decayed teeth $(\mathrm{dmft})$ and 1.86 decayed tooth surfaces (dmfs). The basic demographic factors which address the correlation between SES and ECC prevalence are given in Tables 1 and 2. The highest disease frequency (35.1\%) was found in male children $(\mathrm{p}=0.038)$, who did not speak Serbian

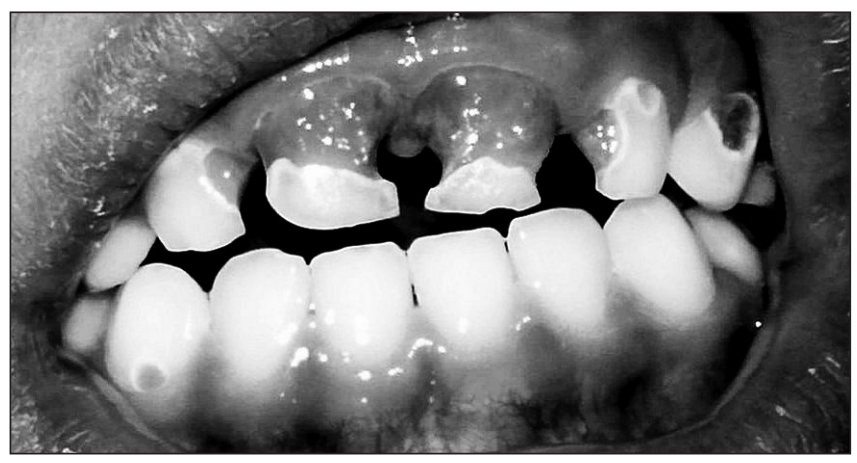

Fig. 1. Severe form of early childhood caries with complications. 
Table 1. Influence of children's social environment on early childhood caries prevalence $(N=341)$

\begin{tabular}{|c|c|c|c|c|c|c|c|c|}
\hline \multirow{2}{*}{\multicolumn{2}{|c|}{ Socio-demographic data }} & \multicolumn{2}{|c|}{ Children with ECC } & \multicolumn{2}{|c|}{ Caries-free children } & \multicolumn{2}{|c|}{ Total } & \multirow{2}{*}{$\begin{array}{c}x^{2} \\
p<0.05\end{array}$} \\
\hline & & $\mathrm{n}$ & $\%$ & $\mathrm{n}$ & $\%$ & $\mathrm{n}$ & $\%$ & \\
\hline \multirow{2}{*}{$\begin{array}{l}\text { Sex } \\
\text { of the child }\end{array}$} & Male & 67 & 35.1 & 124 & 64.9 & 191 & 100.0 & \multirow{2}{*}{0.038} \\
\hline & Female & 37 & 24.7 & 113 & 75.3 & 150 & 100.0 & \\
\hline \multirow{2}{*}{$\begin{array}{l}\text { Language } \\
\text { at home }\end{array}$} & Serbian & 82 & 27.9 & 212 & 72.1 & 294 & 100.0 & \multirow{2}{*}{0.009} \\
\hline & Non-Serbian & 22 & 46.8 & 25 & 53.2 & 47 & 100.0 & \\
\hline \multirow{3}{*}{$\begin{array}{l}\text { Birth order } \\
\text { in family }\end{array}$} & First & 43 & 24.6 & 132 & 75.4 & 175 & 100.0 & \multirow{3}{*}{0.004} \\
\hline & Second & 31 & 30.4 & 71 & 69.6 & 102 & 100.0 & \\
\hline & All others & 30 & 46.9 & 34 & 53.1 & 64 & 100.0 & \\
\hline \multirow{2}{*}{$\begin{array}{l}\text { Child } \\
\text { in kindergarten }\end{array}$} & Yes & 91 & 28.7 & 226 & 71.3 & 317 & 100.0 & \multirow{2}{*}{0.009} \\
\hline & No & 13 & 54.2 & 11 & 45.8 & 24 & 100.0 & \\
\hline
\end{tabular}

ECC - early childhood caries

Table 2. Influence of parents' socioeconomic factors on early childhood caries prevalence

\begin{tabular}{|c|c|c|c|c|c|c|c|c|}
\hline \multirow{2}{*}{\multicolumn{2}{|c|}{ Parents' socioeconomic factors }} & \multicolumn{2}{|c|}{ Children with ECC } & \multicolumn{2}{|c|}{ Caries-free children } & \multicolumn{2}{|c|}{ Total } & \multirow{2}{*}{$\begin{array}{c}x^{2} \\
p<0.05\end{array}$} \\
\hline & & $\mathrm{n}$ & $\%$ & $\mathrm{n}$ & $\%$ & $\mathrm{n}$ & $\%$ & \\
\hline \multirow{4}{*}{$\begin{array}{l}\text { Education } \\
\text { level }\end{array}$} & Without education & 8 & 53.3 & 7 & 46.7 & 15 & 100.0 & \multirow{4}{*}{0.001} \\
\hline & Elementary & 16 & 59.3 & 11 & 40.7 & 27 & 100.0 & \\
\hline & Secondary & 66 & 28.2 & 168 & 71.8 & 234 & 100.0 & \\
\hline & University & 14 & 21.5 & 51 & 78.5 & 65 & 100.0 & \\
\hline \multirow{3}{*}{ Working status } & Unemployed & 36 & 42.9 & 48 & 57.1 & 84 & 100.0 & \multirow{3}{*}{$<0.001$} \\
\hline & Part time employed & 17 & 47.2 & 19 & 52.8 & 36 & 100.0 & \\
\hline & Employed & 51 & 23.1 & 170 & 76.9 & 221 & 100.0 & \\
\hline \multirow{5}{*}{$\begin{array}{l}\text { Family income } \\
\text { per month } \\
\text { (Euro) }\end{array}$} & $<100.00$ & 12 & 41.4 & 17 & 58.6 & 29 & 100.0 & \multirow{5}{*}{0.023} \\
\hline & $100.01-200.00$ & 16 & 47.1 & 18 & 52.9 & 34 & 100.0 & \\
\hline & $200.01-400.00$ & 37 & 34.3 & 71 & 65.7 & 108 & 100.0 & \\
\hline & $400.01-800.00$ & 29 & 23.2 & 96 & 76.8 & 125 & 100.0 & \\
\hline & $>800.00$ & 10 & 22.2 & 35 & 77.8 & 45 & 100.0 & \\
\hline
\end{tabular}

ECC - early childhood caries

Table 3. Influence of socioeconomic status and health information level of parents on early childhood caries severity (\%)

\begin{tabular}{|c|c|c|c|c|c|c|c|c|c|}
\hline \multirow{2}{*}{\multicolumn{2}{|c|}{$\begin{array}{l}\text { Socioeconomic status and health } \\
\text { information level of parents }\end{array}$}} & \multirow{3}{*}{$\begin{array}{c}\text { Caries-free } \\
\text { children }\end{array}$} & \multicolumn{6}{|c|}{ ECC severity } & \multirow{2}{*}{$\begin{array}{c}x^{2} \\
p<0.05\end{array}$} \\
\hline & & & \multirow{2}{*}{$\begin{array}{l}\text { Type } 1 \\
10.60\end{array}$} & \multirow{2}{*}{$\begin{array}{c}\text { Type } 2 \\
11.40\end{array}$} & \multirow{2}{*}{$\frac{\text { Type } 3}{5.15}$} & \multirow{2}{*}{$\begin{array}{c}\text { Type } 4 \\
6.65\end{array}$} & \multirow{2}{*}{$\frac{\text { Type } 5}{8.60}$} & \multirow{2}{*}{$\frac{\text { Total } \%}{100.00}$} & \\
\hline \multirow{3}{*}{$\begin{array}{l}\text { Working } \\
\text { status }\end{array}$} & Unemployed & & & & & & & & \multirow{3}{*}{0.029} \\
\hline & Part time employed & 58.95 & 10.20 & 9.30 & 7.65 & 2.80 & 11.50 & 100.00 & \\
\hline & Employed & 74.20 & 7.15 & 9.90 & 3.40 & 2.00 & 2.20 & 100.00 & \\
\hline \multirow{3}{*}{$\begin{array}{l}\text { Health } \\
\text { information } \\
\text { level }\end{array}$} & Uninformed & 46.90 & 11.15 & 11.95 & 13.50 & 5.30 & 11.25 & 100.00 & \multirow{3}{*}{0.010} \\
\hline & On average informed & 72.70 & 7.80 & 9.85 & 2.70 & 2.70 & 4.30 & 100.00 & \\
\hline & Well informed & 76.65 & 4.35 & 10.95 & 4.05 & 0.00 & 4.05 & 100.00 & \\
\hline \multirow{5}{*}{$\begin{array}{l}\text { Family } \\
\text { income per } \\
\text { month (Euro) }\end{array}$} & $<100.00$ & 54.20 & 10.30 & 13.80 & 3.40 & 6.50 & 11.80 & 100.00 & \multirow{5}{*}{0.008} \\
\hline & $100.01-200.00$ & 55.20 & 5.90 & 11.80 & 14.20 & 2.60 & 10.30 & 100.00 & \\
\hline & $200.01-400.00$ & 68.70 & 9.30 & 13.00 & 1.90 & 3.40 & 3.70 & 100.00 & \\
\hline & $400.01-800.00$ & 76.80 & 8.00 & 7.20 & 2.40 & 0.80 & 4.80 & 100.00 & \\
\hline & $>800.00$ & 77.80 & 4.40 & 8.90 & 6.70 & 0.00 & 2.20 & 100.00 & \\
\hline
\end{tabular}

ECC - early childhood caries 
language (46.8\%, $\mathrm{p}=0.009)$, in the third and next born child in the family $(46.9 \%, \mathrm{p}=0.004)$ and in children who did not attend the kindergarten $(54.2 \%, \mathrm{p}=0.009)$ (Table 1$)$. The highest prevalence of ECC was found in children of part-time employed parents $(47.2 \%, p<0.001)$, who had elementary education $(59.3 \%$, $\mathrm{p}=0.001)$, and in low income families with 100.01-200.00€ per month $(47.1 \%, p=0.023)$ (Table 2$)$. The analysis of SES influence on ECC severity showed the higher prevalence of 1, 2, 4 types of disease in children of unemployed parents, and types 3 and 5 in children of part time employed parents (Table 3 ). In addition, reduced prevalence of all ECC types was observed in children of parents who were average and/or well informed about oral health. All types of ECC were more frequent in children whose parents were not informed about oral health $(p=0.010)$. The lowest prevalence of all ECC types was noticed in children whose parents had the monthly income higher than $200 €$. Concerning ethnicity, the highest ECC frequency was found in Roma (Gipsy) children $(50.0 \%)$ as well as in those of Ruthenian (43.8\%), Slovakian $(37.8 \%)$, and Serbian origin $(26.1 \%)$

\section{DISCUSSION}

This study analysed the prevalence of ECC and its relationship with socio-behavioural factors, language disparity and ethnicity. The ECC prevalence in SBD of $30.5 \%$, was in range of moderate values of prevalence compared to low prevalence in Sweden (2) and high prevalence in Middle-East (12), Asian countries (10) and in Hispanic-Americans (5). Regarding surrounding countries, Munteanu (16) stated that in Romania $40.29 \%$ of children 25-71 months old had ECC - the values were higher than in our study. Our research showed that every child had, on average, 0.87 deciduous teeth with caries i.e. 1.86 decayed tooth surfaces and it was in agreement with Willems (17) data $(0.83 \pm 1.22)$. Our findings also correlated with those of Santos and Soviero (18) who revealed the mean dmfs $1.7 \pm 2.5$ in three-year old children in Brazil. ECC appeared to be more frequent in male children, and this is similar to the results of Abu Hamila (19). The rationale for the gender difference is unclear but it has been reported that male children have 13 time greater risk of caries development (20) and the possible earlier "vertical" and "horizontal" transmission of mutant streptococci (MS) from mothers to male children (21). Whether gender differences in the prevalence of ECC are the result of better oral hygiene in girls (14) or a culturally conditioned different diet of male children (22), will be shown by future research. Furthermore, the third and every next born child in a family have a higher risk for ECC as confirmed in Prakash et al. study (23). Severe form of ECC along with prevalence rate was lower in children who attended the kindergarten, in spite of a proven higher possibility for "horizontal" MS transmission. The reason for this was explained by Wendt et al. (24), who reported a more balanced diet and intensive health-educational work in kindergartens. Moreover, ECC frequency in the children of highly educated parents was considerably reduced compared to the children whose parents had elementary or no education at all, as confirmed by Schroth et al. (13) and Borges et al. (25). Considering the fact, that the existing network of educational institutions in SBD is not adjusted to the population's demographic, socioeconomic or multilingual educational needs, it is quite possible to expect a continued increase of ECC. Employed parents had three times less children with ECC compared to the unemployed ones, as also reported by Tiwari et al. (26). This may be explained by higher health educational level of employed parents, and by the fact that their children more often stay in the kindergarten. However, the further increase of ECC could be expected because of the increased unemployment trend rate primarily affects some minority young people in Serbia (future parents). The monthly income of the parents was shown to be a significant risk factor for the prevalence and severity of ECC. It was the lowest in children whose parents had a monthly income greater than $800,00 €$, that was in accordance with Tiwari et al. survey (26), who found a linear increase of prevalence and more severe ECC types with decreased levels of parental annual income. The wealthy families have the ability to provide more quantitatively and qualitatively balanced foods, fluoride prophylaxis and improved oral hygiene for their children. Further, the children of the unemployed and part-time working parents had the highest prevalence of initial, moderate and severe ECC types, and this correlates with the results from Schroth et al. (13). The part-time working mothers very often had no health insurance and the dental services were not readily available to them (6). In our study, significantly lower prevalence of all types of ECC was noticed in children of employed parents and this could be related to the higher education, health information levels and monthly income. All types of ECC appeared to be more frequent in the children of the poor health informed parents as confirmed by Calcagnile et al. (27). Their study pointed out that the prevalence and severity of ECC is associated with parents' knowledge and willingness to change their behaviour with the aim of preserving their own as well as their children's oral health. Therefore, implementation of parental "healthy" behaviour, attitudes and habits would be in the future an important framework for the eradication of ECC risk factors. Based on the last census data presented in the official Report of the Institute of Statistics of the Republic of Serbia (28), 26 nationalities were defined as multi-ethnic population in northern part of the country that is related to SBD. Among them, the highest ECC prevalence was noted in Roma children, then Ruthenian, Slovakian and other nationalities, who did not speak the Serbian language. Çolak et al. (4) reported that children of ethnic minorities and immigrants in the Netherlands, England and Finland had higher ECC prevalence compared to other children in these countries. They also could not speak the official language of the country in question. It is necessary to stress that the spoken language was the basis of education, socialization and equal participation in all spheres of social life. The children who could not understand the Serbian language, apart from ethnicity, were more exposed to ECC. This specific situation leads to a more difficult approach to health information and mass media for those population, and consequently to a lower level of health education, and increased possibility for ECC. A number of studies showed a higher risk for ECC in children of certain ethnic background $(1,7,11,13,19)$. This could be explained by cultural and educational norms as well as by misapprehension of the importance of the primary teeth and oral health in general (29) and/or the low SES $(6,11,13,17)$. The children's distrust and fear of going to the dentist and the parent's widely spread belief that primary teeth should not be treated creates a "circulus vitiosus" and may lead to the higher ECC prevalence. Our study 
also revealed an urgent need for understanding the problem of "multilingualism" of the minority population groups living in SBD and elsewhere. Common understanding of multilingual disparity including education, the public health and culture of the territorial and immigrant minorities have the great repercussion on dental morbidity. The low level of understanding between parentchild-dentist, as result of the language barriers can lead to distrust and feeling of discrimination among the parents themselves and their children as well.

\section{Recommendations}

- Educating dentists from the health centres to take a more active role in community based and public health activities concerning primary prevention of dental diseases as well as early ECC screening unlike the current therapeutic approach of the disease treatment;

- Improving the collaboration with the primary care physicians in recognizing the early signs of ECC and in referring those patients to the dentist;

- Recommendation to the Public Health Authorities and policy makers to include the private dental practices in the public healthcare system to enable promotion of primary preventive measures and therefore contribute significantly to the infant's oral health;

- There is also the necessity to fulfil the certain presence gap between researchers engaged in facilitation of the communication through language and cultural barriers and those engaged in the prevention of ECC risk factors;

- Overcoming the language disparity by people chosen from ethnic minorities as specific type of "mediator profile" - "New Speakers", could be a completely new approach for ECC prevention. Firstly, mediators could linguistically adopt health educational programmes for minority groups that address their specific ethnic habits, customs, religion and culture. Mediators could also try to get to the isolated population groups like Roma who more often have no healthcare coverage and live in certain ethnic, social and cultural "closed groups" that may place them in a disadvantaged position in regard to the rest of population;

- "New Speakers", minority mediators, could be the perfect link between our research team and the final users of this action study results, such as the organization of the public sectors engaged in the health problems of patients of different national and social status (hospitals, schools, social institutions), as well as the nongovernment organizations performing issues of multilingual regional minorities, immigrants, newcomers and refugees;

- Recommendation to the public health authorities and policy makers for their financial support concerning public health activities on ECC prevention for vulnerable high risk children without healthcare insurance, particularly the low income families (Roma and other poor ethnic minorities and refugees) in a targeted manner;

- Finally, emphasizing the ECC as community problem through the "NET" of different scientific field of researches (public health educators, linguists, psychologists, social workers, sociologists, policy makers, economics, dentists, etc.), along with mediators' help enable the dentists in completely new manner to have an open dialog with multilingual minorities, the refugees and newcomers and therefore insure efficient access to the dental care for those people.

We do sincerely hope that our suggestion for this specific type of the cooperation - "NET" would also contribute to the lower ECC prevalence, especially in the multi-ethnic parts of different countries.

\section{CONCLUSIONS}

ECC is a serious health problem especially among the socially and ethnic disadvantaged groups in the South Backa District. The complex interaction of risk factors like social environment, ethnicity and Serbian language ignorance had a significant influence on the prevalence and severity of ECC in preschool children of this multi-ethnic and multilingual region. Decreased trends of ECC prevalence could be achieved by engaging the public with the aim of reorganization of the social values and policy priorities in addressing the burden of poverty, ethnicity as well as the language barriers.

\section{Acknowledgements}

We wish to express special appreciation for valuable professional help, support and encouragement received in the preparation and review of our manuscript to Professor Jack Toumba, Head of Paediatric and Preventive Dentistry, University of Leeds School of Dentistry, England and Vesna Zivojinovic Toumba, DDS, MDS, PhD.

The manuscript is the part of the Provincial Public Health Programme "Early childhood caries in Vojvodina" No: 114-451-1432/2014-02, and Cost Action IS 1306 European Project "New Speakers in a Multilingual Europe: Opportunities and Challenges".

We would also like to acknowledge the important help and financial support of the Provincial Secretariat for Science and Technological Development, Republic of Serbia.

\section{Conflict of Interests}

None declared

\section{REFERENCES}

1. Schroth RJ, McNally M, Harrison R. Pathway to oral health equity for first nations, Métis, and Inuit Canadians: knowledge exchange workshop. J Can Dent Assoc. 2015;80:f1.

2. Bankel M, Eriksson UC, Robertson A, Köhler B. Caries and associated factors in a group of Swedish children 2- 3 years of age. Swed Dent J. 2006;30(4):137-46.

3. Shrivastava R, Couturier Y, Girard F, Papineau L, Emami E. Two-eyed seeing of the integration of oral health in primary health care in Indigenous populations: a scoping review. Int J Equity Health. 2020;19:107. doi: 10.1186/s12939-020-01195-3.

4. Çolak H, Dülgergil CT, Dalli M, Hamidi MM. Early childhood caries update: a review of causes, diagnoses and treatments. J Nat Sci Biol Med. 2013;4(1):29-38.

5. Huntington NL, Kim IJ, Hughes CV. Caries-risk factors for Hispanic children affected by early childhood caries. Pediatr Dent. 2002 NovDec;24(6):536-42.

6. Bhardwaj SV, Bhardwaj A. Early childhood caries and its correlation with maternal education level and socio-economic status. J Orofac Sci. 2014;6(1):53-7.

7. Nunes AMM, Silva AAMD, Alves CMC, Hugo FN, Ribeiro CC. Factors underlying the polarization of early childhood caries within a high-risk 
population. BMC Public Health. 2014;14:988. doi: 10.1186/1471-245814-988.

8. Policy on early childhood caries: classifications, consequences, and preventive strategies. In: American Academy of Pediatric Dentistry. The reference manual of pediatric dentistry [Internet]. Chicago: American Academy of Pediatric Dentistry; 2016 [cited 2019 March 27]. p. 79-81. Available from: https://www.aapd.org/media/policies_guidelines/p_eccclassifications.pdf.

9. Singh S, Vijayakumar N, Priyadarshini HR, Shobha M. Prevalence of early childhood caries among 3-5 year old pre-schoolers in schools of Marathahalli, Bangalore. Dent Res J (Isfahan). 2012;9(6):710-4.

10. Zhang S, Liu J, Lo ECM, Chu CH. Dental caries status of Bulong preschool children in Southwest China. BMC Oral Health. 2014;14:16. doi: 10.1186/1472-6831-14-16.

11. Chandramohan S, Mandava P. Prevalence of early childhood caries among Anganwadi school children in rural areas of Thiruvallur District. Indian Streams Res J. 2014;4(2):1-7.

12. Inayat N, Mujeeb F, Shad MA, Rashid S, Hosein T. Experience of early childhood caries in children at Fatima Jinnah Dental College Hospital Karachi and its relationship with feeding practices. J Pak Dent Assoc. 2010;19(1):34-41.

13. Schroth RJ, Smith PJ, Whalen JC, Lekic C, Moffatt ME. Prevalence of caries among preschool-aged children in a northern Manitoba community. J Can Dent Assoc. 2005;71(1):27.

14. Tusek I, Carevic M, Tusek J. The influence of social environment on early childhood caries. Srp Arh Celok Lek. 2011;139(1-2):18-24. (In Serbian.)

15. Obradović $\mathrm{M}$, Dolić $\mathrm{O}$, Sukara S. Caries prevalence among 24 to 71 -month old children from Banja Luka. Balk J Dent Med. 2016;20(3):168-71.

16. Munteanu A, Luca R, Farcaşiu C, Stanciu I. Caries experience in children with severe early childhood caries. Rom J Oral Rehab. 2011;3(4):72-6.

17. Willems S, Vanobbergen J, Martens L, Maesener JD. The independent impact of household and neighbourhood-based social determinants on early childhood caries. Fam Community Health. 2005;28(2):168-75.

18. Santos AP, Soviero VM. Caries prevalence and risk factors among children aged 0 to 36 months. Pesqui Odontol Bras. 2002 Jul-Sep;16(3):203-8.

19. Abu Hamila NAA. Early childhood caries and certain risk factors in a sample of children 1-3.5 years in Tanta. Dentistry. 2013;4(1):180. doi: 10.4172/2161-1122.1000180.
20. Arora A, Scott JA, Bhole S, Do L, Schwarz E, Blinkhorn AS. Early childhood feeding practices and dental caries in preschool children: a multi-center birth cohort study. BMC Public Health. 2011;11:28. doi: 10.1186/1471-2458-11-28.

21. Doméjean S, Zhan L, DenBesten PK, Stamper J, Boyce BT, Featherstone JD. Horizontal transmission of mutans streptococci in children. J Dent Res. 2010;89(1):51-5.

22. Lukacs PJ. Gender differences in oral health in South Asia: metadata imply multifactorial biological and cultural causes. Am J Hum Biol. 2011;23(3):398-411.

23. Prakash P, Subramaniam P, Durgesh BH, Sapna Konde S. Prevalence of early childhood caries and associated risk factors in preschool children of urban Bangalore, India: a cross-sectional study. Eur J Dent. 2012;6(2):141-52.

24. Wendt LK, Hallosten AL, Koch G, Birkhed D. Analysis of caries related factors in infants and toddlers living in Sweden. Acta Odontol Scand. 1996;54(2):131-7.

25. Borges HC, Garbín CA, Saliba O, Saliba NA, Moimaz SA. Sociobehavioral factors influence prevalence and severity of dental caries in children with primary dentition. Braz Oral Res. 2012;26(6):564-70.

26. Tiwari T, Quissell DO, Henderson WG, Thomas JF, Bryant LL, Braun PA, et al. Factors associated with oral health status in American Indian Children. J Racial Ethn Health Disparities. 2014;1(3):148-56.

27. Calcagnile F, Pietrunti D, Pranno N, Di Giorgio G, Ottolenghi L, Vozza I. Oral health knowledge in pre-school children: a survey among parents in central Italy. J Clin Exp Dent. 2019;11(4):e327-33. doi: 10.4317/ jced.55378.

28. 2011 Census of population, households and dwellings in the Republic of Serbia. Population. Religion, mother tongue and ethnicity. Belgrade: Statistical Office of the Republic of Serbia; 2013. (In Serbian, English.)

29. Baghdadi ZD. Improving oral health status of children in Tabuk, Saudi Arabia. Dent J. 2014;2:22-40.

Received June 11, 2020 Accepted in revised form November 15, 2020 